\title{
Resveratrol Protects Murine Chondrogenic ATDC5 Cells Against LPS-Induced Inflammatory Injury Through Up- Regulating MiR-146b
}

Hui Jin ${ }^{a}$ Hong Zhang ${ }^{b}$ Tingjian Ma ${ }^{a}$ Hongjia Lan ${ }^{a}$ Shibin Haiyan Zhu ${ }^{a}$ Youbo Jia

aDepartment of Orthopedic, The Second Hospital of Jilin Universit Clinical Medicine, Changchun Medical College, Changchun, China

Key Words

Resveratrol • Osteoarthritis - ATDC5 ce

\section{Abstract}

Background/Aims: Resverat for osteoarthritis treatment, $\mathrm{W}$ this study is to decode on Mouse chondrogenic ce for $12 \mathrm{~h}$, after which ce were assessed. The nres transfection, ar

The IC50 value, $f$ repressed RSV pr

via ( im tly, miR-146b was up-regulated by RSV, and the protective functions of RSV SC5 c ere attenuated by miR-146b silence. Further, NF-KB and p38MAPK pathways tivatea by LPS, and were deactivated by RSV. Besides, RSV-induced the deactivation of J8MAPK pathways was reversed by miR-146b silence. Conclusions: Our findings sgest that RSV protects ATDC5 cells from LPS-induced inflammatory and apoptotic injury 1a -regulation of miR-146b and thereby deactivation of NF-kB and p38MAPK pathways.

\section{Introduction}

(C) 2018 The Author(s) Published by S. Karger AG, Basel

Osteoarthritis, a degenerative joint disease commonly affects the knee, is a leading cause of disability worldwide [1]. Joint inflammation, cartilage breakdown and bone remodeling contribute to a syndrome of chronic pain, stiffness and impaired movement

\begin{tabular}{ll}
\hline Youbo Ji & Department of Orthopedic, The Second Hospital of Jilin University \\
& No. 218, Ziqiang Street, Changchun, Jilin 130041 (China) \\
& Tel. +86-431-81136747, Fax +86-431-81136747, E-Mail youbo1226@sohu.com
\end{tabular}

\section{KARGER}




\section{Cellular Physiology

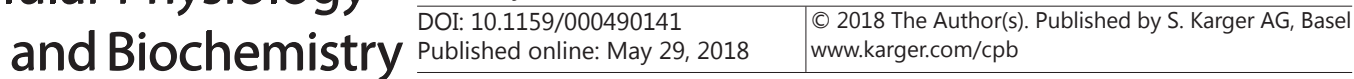 \\ Jin et al.: Protective Role of Resveratrol in Cartilage}

[2]. Recent years, the prevalence of osteoarthritis is significantly increased with the rapid increase of aging population and the rising obesity. According to patient's needs, anatomical distribution, disease phase and progression, as well as comorbidities, osteoarthritis patients are always managed by supportive nonpharmacological therapy, systemic pharmacological therapy, localized intra-articular therapy, and surgery [2]. However, an ongoing treatme gap for patients with osteoarthritis is still remaining $[3,4]$, which calls for effective treatmen options.

Resveratrol (RSV), 3, 4',5-trihydroxy-trans-stilbene, is a polyphenolic phytoalexin is produced by a wide variety of plants, berries, and fruits, and is mainly fornd in $g$ skin and red wine [5]. Numerous studies have reported RSV as an anti-o.dtive, inflammatory, anti-apoptotic, chemoprotective, anti-diabetic, anti-cancer, anc agent [6-11]. In vitro evidences have demonstrated that RSV suppress inflammatory signaling and apoptosis in human chondrocytes, implyin RSV for use in the treatment of osteoarthritis $[12,13]$. In a rat model of poten RSV for use in the treatment of osteoarthritis $[12,13]$. In a rat model of ${ }^{3}$, KSV significantly inhibited the induction of clinical scores in rats with osteon itis [ rother in vivo study mentioned that RSV prevented the progression of osteo itis by decreasing chondrocyte apoptosis [15]. The anti-inflammatory and apopto "ects of RSV in these studies were observed, and suggested RSV as a p sup cmentation for osteoarthritis treatment. But, to date, the mechanisms und ing rotective functions towards chondrocyte are still unclear and need to be decods

microRNAs (miRNAs) are a group of shor ${ }^{+}$-coding $\mathrm{k}$ miRNAs were previously recognized as "noise DNA", but recent studies nced then key regulators in a wide range of biochemical pathways, including cell $r$ tion, apoptosis, differentiation, and autophagy. Aberrant miRNA levels have been ser osteoarthritis [16], and some of them have been considered as therapeutic $t$ ts, ? divery of miRNA can modify the process of osteoarthritis [17]. miR-146 a post-transcriptional gene silencer, which is critical in the control of imm e onse [18]. It has been previously shown that miR-146b was up-regulated in chond cartilage, suggesting miR-14 on matory mediator in chondrocyte [19]. The specific aim of this study is lore wriether miR-146b is implicated in the protective functions of RSV on LPS-ip red genic cells.

\section{Materials and Meth.}

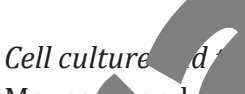

Mouse ndr ni line ATDC5 was purchased from European Collection of Authenticated Cell Cult ECAC on Down, Wiltshire, UK). The cells were cultured in DMEM: Ham's F-12 (1:1) n dirm (. Aldrich, St. Louis, MO, USA) supplemented with $2 \mathrm{mM}$ Glutamine (Sigma-Aldrich) and 5\% Jovine (FBS, Gibco, Grand Island, NY, USA). The cells were maintained at $37^{\circ} \mathrm{C}$ in a humidified $r$ with $\mathrm{N}_{0} \mathrm{CO}_{2}$. Subcultures were obtained after 2-3 days of culturing using trypsin/EDTA solution i). All cells were used between the fifth and tenth passages.

LPS Irom Escherichia coli 0111:B4 was purchased from Sigma-Aldrich. LPS with concentrations an from 0 to $20 \mu \mathrm{g} / \mathrm{ml}$ were used to treat ATDC5 cells for $12 \mathrm{~h}$ to stimulate inflammatory injury. RSV with purity greater than 99\% was purchased from Sigma-Aldrich. RSV was dissolved in DMSO 99.7\%, Sigma-Aldrich) and made up with the medium so that the final concentration of the DMSO was less than $0.1 \%$. 0.1\% DMSO without RSV was used as a blank control. ATDC5 cells were treated by 0-50 $\mu \mathrm{M}$ RSV for $24 \mathrm{~h}$ before LPS treatment.

Cell viability assay

ATDC5 cells were seeded in 96-well plates with a density of 5000 cells/well. After adherence, the culture medium was replaced by fresh medium containing $30 \mu \mathrm{M} \mathrm{RSV}$. The plates were incubated at $37^{\circ} \mathrm{C}$ for $24 \mathrm{~h}$, followed by $12 \mathrm{~h}$ treatment with $10 \mu \mathrm{g} / \mathrm{ml}$ LPS. After treatment, the cells in each group were washed twice with PBS and then $20 \mu \mathrm{l}$ Cell Counting Kit-8 (CCK-8, Dojindo Molecular Technologies, Gaithersburg,

\section{KARGER}




\section{Cellular Physiology Cell Physiol Biochem 2018;47:972-980

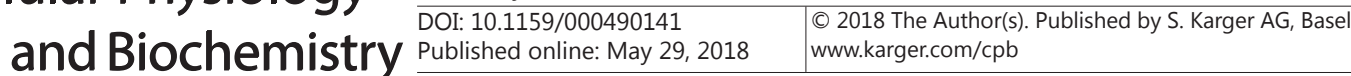 \\ Jin et al.: Protective Role of Resveratrol in Cartilage}

MD) was added into each well and incubated for another $4 \mathrm{~h}$ at $37^{\circ} \mathrm{C}$. The absorbance was measured using a Microplate Reader (Bio-Rad, Hercules, CA, USA) at a wavelength of $450 \mathrm{~nm}$.

\section{Apoptosis assay}

Annexin V-FITC/PI apoptosis detection kit (Beijing Biosea Biotechnology, Beijing, China) was used detect the apoptotic cells. ATDC5 cells were seeded in 6-well plates with a density of $5 \times 10^{5}$ cells/we When the cells were grown to about $80 \% \sim 90 \%$ confluence, RSV and LPS were added simultaneously or respectively. After treatment, the cells were collected and resuspended in $200 \mu$ l Binding Buffer $(1 \times$ cells/sample) containing $10 \mu \mathrm{l}$ Annexin V-FITC and $5 \mu \mathrm{l}$ PI. The adherent and floating cells wore comb The samples were incubated for $30 \mathrm{~min}$ in the dark on ice, and then $300 \mu \mathrm{l}$ PBS was added. (Beckman Coulter, USA) was used to discriminate apoptotic cells (Annexin-V positive and PI-n necrotic cells (Annexin-V- and PI-positive).

\section{ELISA}

ATDC5 cells were grown to about $80 \% \sim 90 \%$ confluence in 6-well plates. Af creat. th RSV and LPS simultaneously or respectively, the culture supernatant of ATDC5 cells llected for use in the detection of inflammatory cytokine concentrations. Mouse IL-1 $\beta$ (Ca+ CSB-E08 mouse IL-6 (Cat. No.: CSB-E04639m), and mouse TNF- $\alpha$ (Cat. No.: CSB-EQ023955 No (Cus 0 , Wuhan, China) were conducted according to the manufacturer's instructions. Optica nsit acted at $450 \mathrm{~nm}$ using the iMark microplate reader (Bio-Rad, Hercules, CA, USA).

\section{miRNA transfection}

For miR-146b silencing, the specific inhipit AGCCUAUGGAAUUCAGUUCUCA was purchased fron Co. (Shanghai, China). A scrambled miRNA was transfected as a negative control (NC). fecti as performed under antibiotic-free in 6-well plates by using Lipofectamine 3000 rea arlsbad, CA, USA). The final concentration of miR-146b inhibitor (anti-miR-146b) and as the transfection was $100 \mathrm{nM}$. At $48 \mathrm{~h}$ of transfection, cells were collected for use in the following

\section{qRT-PCR}

To analyze the mRNA leve cells which were grown in RNA of each sample were s Synthesis Kit (Roche, Rasel, S qRT-PCR. The leve Reverse trar riptic as ormed by using the Mir- $\mathrm{X}^{\mathrm{TM}}$ miRNA First-Strand Synthesis Kit and qRT-PCR was perf by M niRNA qRT-PCR SYBR $®$ Kit (both

f`งm Tak alian, China). U6 was used as a reference for 1 'zing miR-146b expression. Fold changes Iculatea, oy the classic $2^{-\Delta \Delta c t}$ method. The primary equo listed in Table 1.

\section{Mestern blot}

iotal protein in ATDC5 cells which were grown in 24-

ell plates was isolated by cell lysis buffer $(20 \mathrm{mM}$ Tris- $\mathrm{HCl}$ (pH7.4), $150 \mathrm{mM} \mathrm{NaCl}, 1 \mathrm{mM}$ EDTA, 1\% Triton X-100, 1\% $\mathrm{C}_{24} \mathrm{H}_{39} \mathrm{O}_{4} \mathrm{Na}, 1 \%$ SDS and $1 \mathrm{mM}$ PMSF) for $30 \mathrm{~min}$ over ice. The concentration and purity were detected by the $\mathrm{BCA}^{\mathrm{TM}}$ Protein Assay Kit (Pierce, Appleton, WI, USA). The whole-cell extracts were resolved over SDS-PAGE and transferred onto PVDF membranes. The membranes were blocked with 5\% non-fat dry milk for $1 \mathrm{~h}$ at room temperature, followed by incubation with the specific primary antibodies for the detection of pro
Table 1. The primary sequences used in qRT-PCR analysis

\begin{tabular}{|c|c|}
\hline Gene & Sequences \\
\hline IL- $1 \beta$ & $\begin{array}{l}\text { forward, 5'-GCAACTGTTCCTGAACTCAACT-3'; } \\
\text { reverse, 5'-ATCTTTTGGGGTCCGTCAACT-3' }\end{array}$ \\
\hline IL-6 & $\begin{array}{l}\text { forward, 5'-TCCTACCCCAATTTCCAATGC-3'; } \\
\text { reverse, 5'-CCACAGTGAGGAATGTCCACAA-3' }\end{array}$ \\
\hline TNF- $\alpha$ & $\begin{array}{l}\text { forward, 5'-TCTTCCCTGAGGTGCAATGC-3'; } \\
\text { reverse 5'-GCTCCGTTTTCACAGAAAACATG-3' }\end{array}$ \\
\hline miR-146b & $\begin{array}{l}\text { forward, 5'-GGGTGAGAACTGAATTCCA-3'; } \\
\text { reverse 5'-CAGTGCGTGTCGTGGAGT-3' }\end{array}$ \\
\hline U6 & $\begin{array}{l}\text { forward, 5'-CTCGCTTCGGCAGCACATATACT-3'; } \\
\text { reverse, 5'-ACGCTTCACGAATTTGCGTGTC-3' }\end{array}$ \\
\hline$\beta$-actin & $\begin{array}{l}\text { forward, 5'-GGCTGTATTCCCCTCCATCG-3'; } \\
\text { reverse, 5'-CCAGTTGGTAACAATGCCATGT-3' }\end{array}$ \\
\hline
\end{tabular}




\section{Cellular Physiology

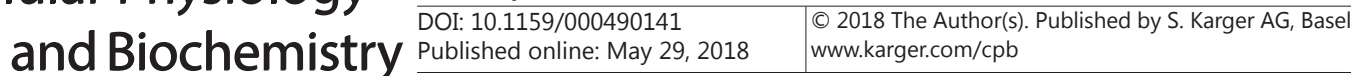 \\ Jin et al.: Protective Role of Resveratrol in Cartilage}

caspase-3 (ab90437), cleaved caspase-3 (ab13847), TNF- $\alpha$ (ab1793), p-p65 (ab86299), p65 (ab32536), p-IкB $\alpha$ (ab133462), IкB $\alpha$ (ab7217), p-p38MAPK (ab47363), p38MAPK (ab170099), $\beta$-actin (ab8226) (Abcam, Cambridge, MA), Bcl-2 (sc-509), Bax (sc-20067), IL-1ß (ab156791), and IL-6 (sc-57315) (Santa Cruz Biotechnology, Santa Cruz, CA, USA). The membranes were probed by the secondary antibodies for $1 \mathrm{~h}$ at room temperature, after which the blots were visualized by enhanced chemiluminescence (ECL) meth The intensity of the bands was quantified using Image Lab ${ }^{\mathrm{TM}}$ Software (Bio-Rad, Hercules, CA, USA).

\section{Statistical analysis}

All experiments were done in triplicate. Data represented as mean \pm SD. Statistical differances bet two or more groups were analyzed on SPSS 19.0 statistical software (SPSS Inc., Chicago, I one-way analysis of variance (ANOVA) with Duncan procedure. A $p$-value of $<0.05$ was cor significant difference.

\section{Results}

LPS induces apoptotic and inflammatory injury in ATDC ${ }^{\prime l} l_{S}$

To begin with, ATDC5 cells were subjected to an i As a result, viability of ATDC5 cells was significantly red $\mathrm{d} b$ value of LPS toward ATDC5 cells was about $10.27 \mu \mathrm{g} / \mathrm{ml}\left(\mathrm{F}_{\mathrm{f}}\right.$ selected as a LPS-stimulating condition for use the followi indicated that LPS induced a significant increas voptotic $c$ up-regulations of cleaved caspase- 3 and Bax, and vn-regulation of Bcl-2. Moreover, the protein and mRNA levels of pro-inflammator ton (IL-1 $\beta$, IL-6 and TNF- $\alpha$ ) in cell as well as their concentrations in cell culture st nata vere all increased notably by LPS stimulation ( $p<0.05$, Fig. 1D-1F).

\section{RSV protects ATDC5 cells against}

RSV with dosage of $0-5$ viability was monitored by 0 of RSV did not significantl ane $\mu \mathrm{M}$ ) of RSV induced sign on LPS-injured ATDC5 functional analysec-As i the viability of $y$ reduced by RS or $(p<0.05)$, rotei $\mathrm{Ve}$ ant inc $s$ in cell viability $(p<0.05)$. To see the effects of RSV $30 \mathrm{yM}$ was selected as a RSV-treating condition for the further own in Fig. 2B, RSV pre-treatment significantly improved ed cus from $51.6 \%$ to $83.0 \%(p<0.05)$. LPS-induced apoptosis was ent, as the apoptotic cell rate was decreased from $14.1 \%$ to $8.0 \%$ $\mathrm{v}$ of cleaved caspase- 3 and Bax were decreased, and protein level of Bcl-2 w reas $2 \mathrm{C}$ and 2D). It is not surprising that, LPS-induced up-regulation and the rele. IL-1 $\beta, 1 L-6$ and TNF- $\alpha$ were all alleviated by RSV pre-treatment $(p<0.05$, Fig.
Fig.

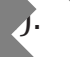

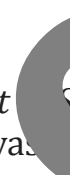

ac injury

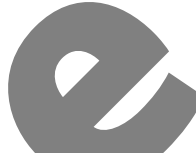


Fig. 2. Effects of RSV on LPS-injured ATDC5 cells. (A) ATDC5 cells were subjected to an increasing dosage of RSV for $24 \mathrm{~h}$, after which cell viability was monitored. (B) Cell viability, (C) Apoptotic cell rate, (D) expression levels of apoptosisrelated proteins, (E) protein levels of pro-inflammatory cytokines, (F) mRNA levels of pro-inflammatory cytokines, and $(\mathrm{G})$ concentrations of pro-inflammatory cytokines in the culture supernatant were assessed, after ATDC5 cells were in turn treated with $30 \mu \mathrm{M}$ RSV for $24 \mathrm{~h}$, and $10 \mu \mathrm{g} / \mathrm{ml}$ LPS for $12 \mathrm{~h} . *$ $\mathrm{p}<0.05$ compared to the indicated group.

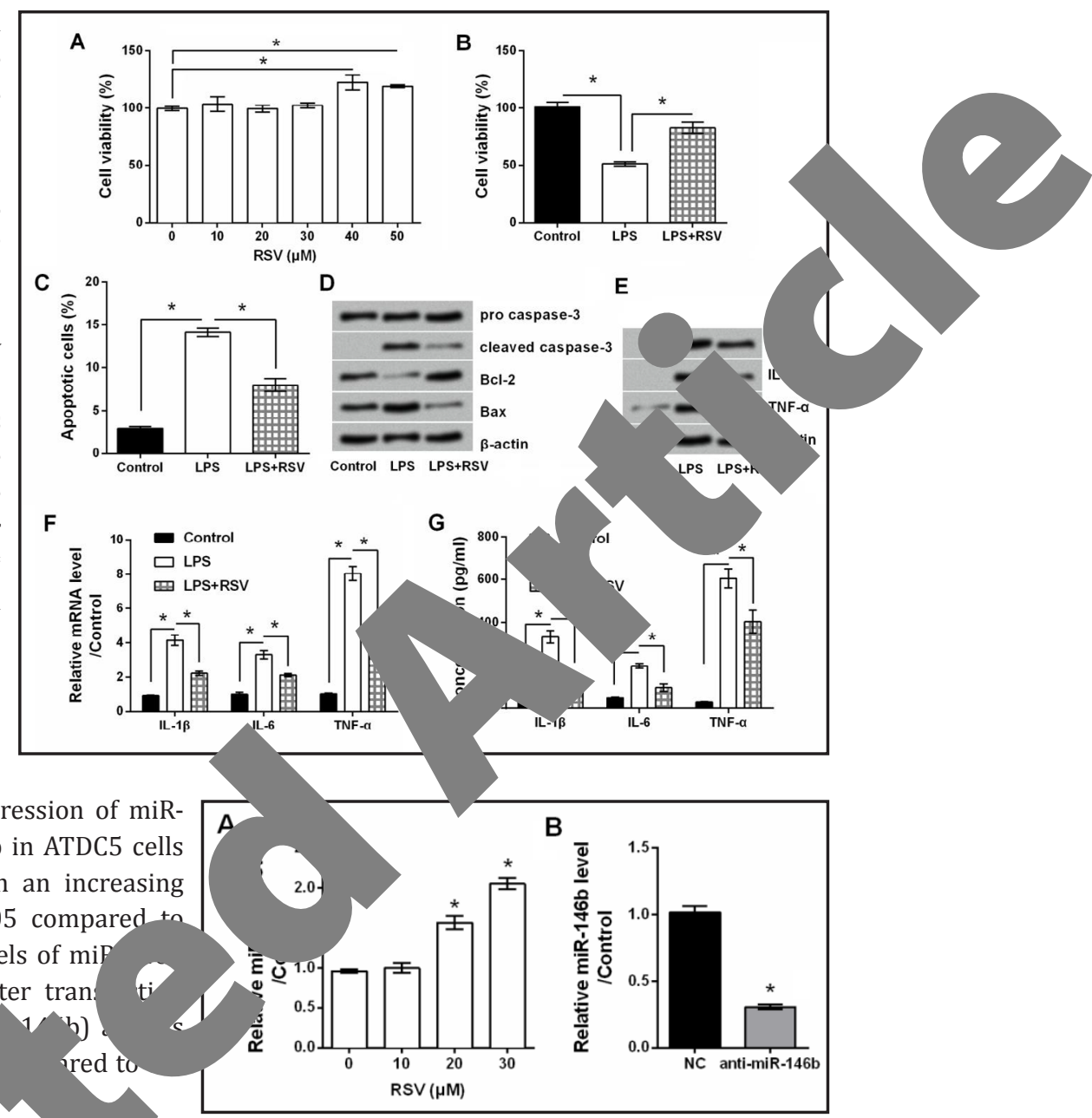

Fig. 3. Effects of RSV on the expression of miR146b. (A) RNA levels of miR-146b in ATDC5 cells were detected after treating with an increasing dosage of RSV for $24 \mathrm{~h}$. * $\mathrm{p}<0.05$ compared $+\infty$ the $0 \mu \mathrm{M}$ RSV group. (B) RNA levels of mip in ATDC5 cells were detected after tran with miR-146b inhibitor (anti-m scrambled control (NC). $*$ p $<0.05$ NC group.

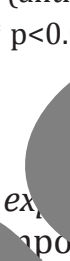

RSV promotes the ex

Considerinc RSV on miR-1 of $\mu \mathrm{M}$ of RSV suite n These $d{ }^{n t}$ : LPS-inj dica in s ficant increases in the RNA levels of miR-146b $(p<0.05$, Fig. 3A) o. vion levels were explored. qRT-PCR data showed that 20 and 30 at miR-146b might be involved in the protective functions of RSV in ATDC5 cells. To verify this hypothesis, the expression of miR-146b in ATDC5 as $\quad$ d by transfection with the specific inhibitor of mmu-miR-146b. Compared NC gro , anti-miR-146b significantly decreased miR-146b expression $(p<0.05$, Fig. 3В).

\section{$2 \gamma$}

RSV protects ATDC5 cells against LPS induced injury via up-regulation of miR-146b

he miR-146b-silenced cells obtained from transfection were in turn treated with and LPS. The increase of cell viability, the decrease of apoptotic cell rate, the downregulations of cleaved caspase- 3 and Bax, as well as the up-regulation of Bcl-2 induced by RSV were attenuated or even abolished by anti-miR-146b transfection ( $p<0.05$, Fig. 4A-4C). Also, the reduced expression and release of IL-1 $\beta$, IL- 6 and TNF- $\alpha$ by RSV were reversed by anti-miR-146b transfection ( $p<0.05$, Fig. 4D-4F).

\section{RSV inactivates NF- $\kappa B$ and p38MAPK pathways via up-regulation of miR-146b}

Western blot analysis was performed to detect the expression changes of core proteins in NF- $\kappa B$ and p38MAPK pathways. As shown in Fig. 5A and 5B, p65, IкB $\alpha$ and p38MAPK were 
Fig. 4. Effects of miR-146b on the protective functions of RSV in ATDC5 cells. (A) Cell viability, (B) Apoptotic cell rate, (C) expression levels of apoptosis-related proteins, (D) protein levels of pro-inflammatory cytokines, (E) mRNA levels of pro-inflammatory cytokines, and (F) concentrations of pro-inflammatory cytokines in the culture supernatant were assessed, after ATDC5 cells were in turn transfected with anti-miR$146 \mathrm{~b}$ or $\mathrm{NC}$, treated with $30 \mu \mathrm{M}$ RSV for $24 \mathrm{~h}$, and treated with $10 \mu \mathrm{g} / \mathrm{ml}$ LPS for $12 \mathrm{~h} .{ }^{*} \mathrm{p}<0.05$ compared to the indicated group.
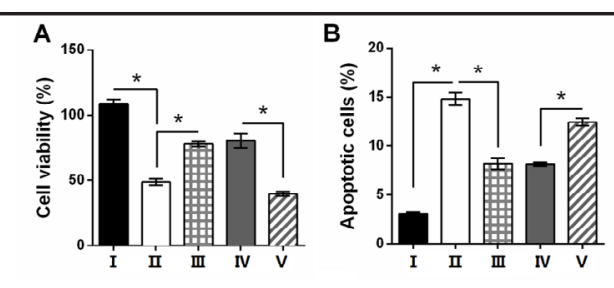

C

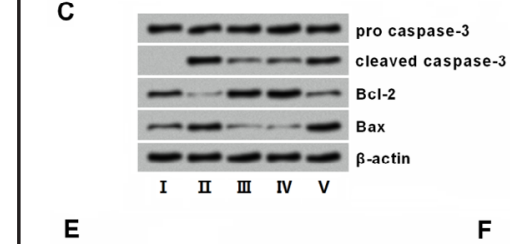

D

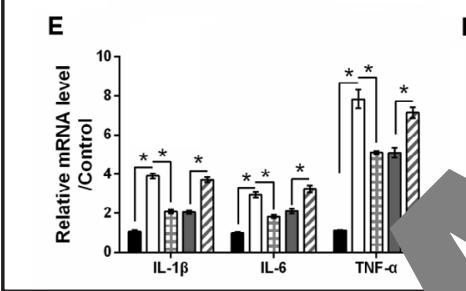

F

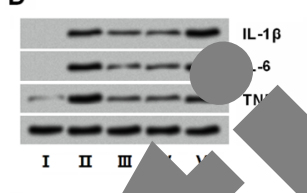

II $\square$ LPS

III 田 LPS $+R S V$

IV $\square$ LPS+RSV+NC
$V \square$ LPS+RSV+anti-miR-146
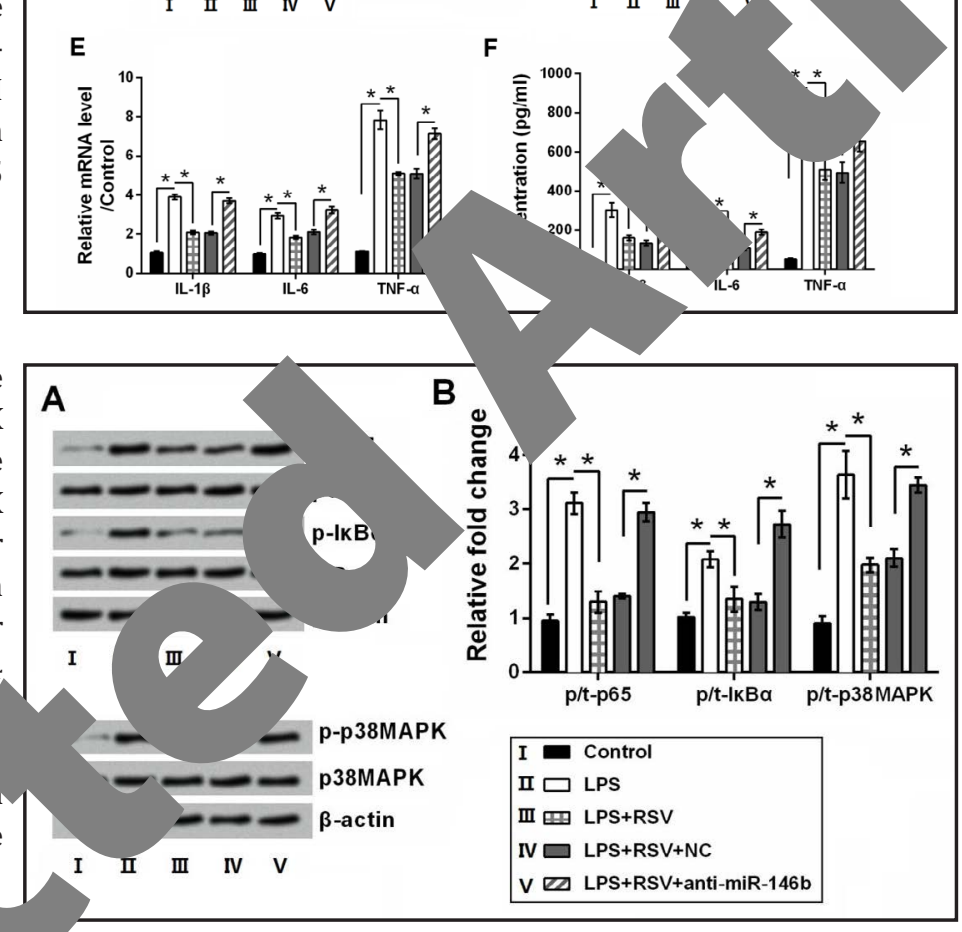

Fig. 5. Effects of RSV on the activation of NF- $\mathrm{B}$ and p38MAPK pathways. (A) Protein levels of core proteins in NF- $\kappa \mathrm{B}$ and p38MAPK pathways were detected, after ATDC5 cells were in turn transfected with anti-miR-146b or $\mathrm{NC}$, treated with $30 \mu \mathrm{M}$ RSV for 24 $\mathrm{h}$, and treated with $10 \mu \mathrm{g} / \mathrm{ml} \mathrm{LP}$ for $12 \mathrm{~h}$. (B) Quantitative analyse based on the intensity of pro bands. * $\mathrm{p}<0.05$ compared indicated group.

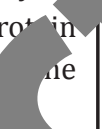

significantly $\mathrm{p}^{\prime} \quad$ ted in response to LPS $(p<0.05)$. LPS-induced phosphorylation of p65, I $\kappa$ B $\alpha$ and $\mathrm{p} 38$ Al cre alleviated by RSV pre-treatment, while RSV could not alleviate the phosn. en anti-miR-146b was transfected into cell $(p<0.05)$.

1. The pathophysiology of osteoarthritis is still unclear, but evidences have proved that or iflammatory cytokines produced from cartilage are released into synovial space and iicipate in the breakdown of articular cartilage, collagen fibers, ligaments and menisci $[20,21]$. Herein, ATDC5 cells were subjected to LPS to induce an in vitro model of cartilage damage. The IC50 value of LPS toward ATDC5 cells was about $10.27 \mu \mathrm{g} / \mathrm{ml}$. Consistent with previous studies [22,23], $10 \mu \mathrm{g} / \mathrm{ml}$ LPS resulted in a significant induction of apoptosis, and a significant release of pro-inflammatory cytokine, indicating LPS induced inflammatory and apoptotic injury in ATDC5 cells. More importantly, RSV could protect ATDC5 cells from LPSinduced cell damage, and miR-146b might be involved in these protective actions.

RSV is a polyphenolic compound found in several plants [5]. The natural function of $\mathrm{RSV}$ is to protect plants against fungal infection, while recent studies suggest it as a possible 


\section{Cellular Physiology

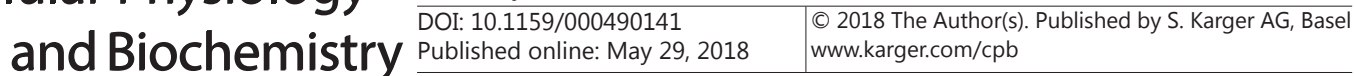 \\ Jin et al.: Protective Role of Resveratrol in Cartilage}

therapeutic option in some organ-specific or systemic autoimmune diseases [24]. RSV is selectively toxic for a wide variety of tumor cells, but is helpful for the growth of a certain number of normal cells, such as endothelial cells, lymphocytes, and chondrocytes [25]. Here, we found that low dosage of RSV $(0-30 \mu \mathrm{M})$ has no significant impact on ATDC5 cells viability, but high dosage of RSV $(40$ and $50 \mu \mathrm{M})$ promoted cell viability. A similar res was reported by Liu and his colleagues [26], suggesting RSV could promote the surviva of ATDC5 cells. Then, $30 \mu \mathrm{M}$ was selected as a RSV-pretreating condition for revealing the functions of RSV on LPS-injured ATDC5 cells. The reason for why we chose $30 \mu \mathrm{M}$ is that should exclude the survival promoting effects of high dosage RSV on cell. We demonstr that RSV switched LPS-induced apoptosis (mitochondrial-dependent) into sur al Bes RSV alleviated LPS-induced inflammation, as the release of IL-1 $\beta$, IL- 6 and 7 significantly repressed by RSV preconditioning. Consistent with previou $28]$, these findings suggested the anti-apoptotic and anti-inflammatory fu. is of $\mathrm{h}$ in ATDC5 cells and provided evidences that RSV might be a promising the osteoarthritis treatment.

It is believed that RSV affects the initiation and progression of several mechanisms. Although no mechanistic link bety RSV has been identified, RSV effects depend at least in the mication of the expression of inflammation-associated miRNAs, such as $-60 \quad 155$, miR-663, and miR-21 [29]. It has been reported that the expression of mik was clevated in response to cytokines or LPS [18]. miR-146b has been nosed to be anti-inflammatory miRNA in chondrocyte [19], and an anti-apoptotic mik dendritic 1 and cardiomyocyte [30, 31]. Herein, we demonstrated that RSV precor induced a significant increase of miR-146b expression, and the protective func is o on ATDC5 cells against LPS were attenuated or even abolished by miR-146b s c. J e data suggest that RSV protects ATDC5 cells against LPS-induced inflar poptotic injury via up-regulation of miR-146b.

In the developing stages of ost various signaling pathways are involved in, including NF- $\mathrm{KB}$ and $\mathrm{p} 3 \mathrm{p}$ pa $38 \mathrm{MAPK}$ can be strongly activated by proinflammatory cytokines, such 1 and rvr $^{-\alpha}$, and $\mathrm{p} 38 \mathrm{MAPK}$ is functional in the regulation of the inflammatory resp $\mathrm{B}$ proteins include p65 (Rel A), Rel B, c-Rel, p50 (NF- $\kappa$ B1) and p52 (NF-r, [33]. . . e cytoplasm of quiescent cells, NF- $\kappa$ B is inactivated by binding with IкBs ( bitor of NF- $\kappa$ B); while under stimulation, a cascade of events was triggered to phocph $B S$ and activate NF- $\kappa B$ pathway [34]. The activation of NF$\kappa B$ pathway pr he transcription of pro-inflammatory genes, including IL-1 $\beta$, IL-6, TNF- $\alpha$ and IL ? ately participates in inflammatory response [35]. There exists an interes or or otween NF- $\kappa$ B and p38MAPK pathways, that the phosphorylated p38MA 11 pr the activation of NF- $\mathrm{kB}$ [36]. In the present study, we found that IS-ind the activations of NF- $\kappa$ B and p38MAPK pathways were alleviated by RSV Iditic and the alleviating effects of RSV were abolished by miR-146b silence. These dicate at NF- $\mathrm{KB}$ and $\mathrm{p} 38 \mathrm{MAPK}$ pathways are involved in the protective functions of 25 cells.

In conclusion, our findings provide evidence that RSV may be a promising therapeutic
n for osteoarthritis treatment, as it protects ATDC5 cells from LPS-induced inflammatory apoptotic injury. Besides, we for the first time suggest that RSV protects ATDC5 cells ossibly by up-regulation of miR-146b and thereby deactivation of NF- $\kappa B$ and p38MAPK pathways.

\section{Disclosure Statement}

The authors declare to have no competing interests. 


\section{Cellular Physiology Cell Physiol Biochem 2018;47:972-980 \begin{tabular}{l|l} 
DOI: 10.1159/000490141 & Ond Biochemistry 2018 The Author(s). Published by S. Karger AG, Basel \\
wwww.karger.com/cpb
\end{tabular} \\ Jin et al.: Protective Role of Resveratrol in Cartilage}

\section{References}

1 Chu CR, Millis MB, Olson SA: Osteoarthritis: From Palliation to Prevention: AOA Critical Issues. J Bone Joint Surg Am 2014;96:e130.

-2 Wehling P, Evans C, Wehling J, Maixner W: Effectiveness of intra-articular therapies in osteoarthritis: a literature review. Ther Adv Musculoskelet Dis 2017;9:183-196.

- 3 Li CS, Karlsson J, Winemaker M, Sancheti P, Bhandari M: Orthopedic surgeons feel that there is a treatment gap in management of early OA: international survey. Knee Surg Sports Traumatol Arthrosc 2014;22:36 378.

4 Buttgereit F, Burmester GR, Bijlsma JW: Non-surgical management of knee osteoarthritis: now and where do we need to go? RMD Open 2015;1:e000027. 2006;5:493-506. Berman AY, Motechin RA, Wiesenfeld MY, Holz MK: The therapeutic potential of res clinical trials. NPJ Precis Oncol 2017;1:35 Injury in Mice: Modulation of Oxidative Stress, Inflammation, and A 2017;2017:9396425. testicular damage in mice. Chem Biol Interact 2017;273:200-211. Ozturk E, Arslan AKK, Yerer MB, Bishayee A: Resver land diabetes. Biomed Pharmacother 2017;95:230-234.

-10 Carlson A, Alderete KS, Grant MKO, Seelig DM, Sharkev. in canine hemangiosarcoma cell lines. Vet Comp or

11 Docherty JJ, Fu MM, Stiffler BS, Limperos RJ, Pokab simplex virus replication. Antiviral Res 1990 -12 Shakibaei M, Csaki C, Nebrich S, Mobashe r. atror suppresses interleukin-1beta-induced inflammatory signaling and apoptosis in $\mathrm{ar}$ chondrocytes: potential for use as a novel nutraceutical for the treatmer ar chondrocytes: potential for use as a
nem Pharmacol 2008;76:1426-1439.

13 Csaki C, Keshishzadeh N, Fisch akibaèr... negulation of inflammation signalling by resveratrol in human chondrocytes in vit Bioć, acol 2008;75:677-687.

14 Wei Y, Jia J, Jin X, Tong W $\mathrm{n}$ H: Resv omeliorates inflammatory damage and protects against osteoarthritis in a rat m of oste arthritis. Mol Med Rep 2018;17:1493-1498.

15 Wang J, Gao JS, Chon JW, _ffect of resveratrol on cartilage protection and apoptosis inhibition in experimental itis or ravbit. Rheumatol Int 2012;32:1541-1548.

16 Kopanska N Ial Gablo N, Gargasz K, Trzeciak M, Zawlik I, Snela S: MiRNA expression in the cartilag fpati w NSteoarthritis. J Orthop Surg Res 2017;12:51.

17 Nug Micro exploring new horizons in osteoarthritis. Osteoarthritis Cartilage 2016;24:573-580.

1) Taga Boldin MP, Chang KJ, Baltimore D: NF-kappaB-dependent induction of microRNA miR-

6, an or targeted to signaling proteins of innate immune responses. Proc Natl Acad Sci U S A 6;103: $481-12486$.

Andres MC, Sanchez-Elsner T, Oreffo ROC: MiR-146b is down-regulated during the chondrogenic difterentiation of human bone marrow derived skeletal stem cells and up-regulated in osteoarthritis. Sci 'ep 2017;7:46704.

Novakofski KD, Torre CJ, Fortier LA: Interleukin-1alpha, -6, and -8 decrease Cdc42 activity resulting in loss of articular chondrocyte phenotype. J Orthop Res 2012;30:246-251.

Loeser RF, Goldring SR, Scanzello CR, Goldring MB: Osteoarthritis: a disease of the joint as an organ. Arthritis Rheum 2012;64:1697-1707.

22 Sun T, Li X, Song H, Gao F, Zhou G, Li X, Chen Z, Chen L: MiR-146a Aggravates LPS-Induced Inflammatory Injury by Targeting CXCR4 in the Articular Chondrocytes. Cell Physiol Biochem 2017;44:1282-1294.

23 Wu DP, Zhang JL, Wang JY, Cui MX, Jia JL, Liu XH, Liang QD: MiR-1246 Promotes LPS-Induced Inflammatory Injury in Chondrogenic Cells ATDC5 by Targeting HNF4gamma. Cell Physiol Biochem 2017;43:2010-2021.

-24 Oliveira ALB, Monteiro VVS: Resveratrol Role in Autoimmune Disease-A Mini-Review. Nutrients 2017;9:E1306 


\section{Cellular Physiology Cell Physiol Biochem 2018:47:972-980 \begin{tabular}{c|c} 
DOI: 10.1159/000490141 & O 2018 The Author(s). Published by S. Karger AG, Basel \\
www.karger.com/cpb
\end{tabular} \\ Jin et al.: Protective Role of Resveratrol in Cartilage}

25 Shakibaei M, Harikumar KB, Aggarwal BB: Resveratrol addiction: to die or not to die. Mol Nutr Food Res 2009;53:115-128.

26 Liu FC, Hung LF, Wu WL, Chang DM, Huang CY, Lai JH, Ho LJ: Chondroprotective effects and mechanisms of resveratrol in advanced glycation end products-stimulated chondrocytes. Arthritis Res Ther 2010;12:R167.

-27 Jin H, Liang Q, Chen T, Wang X: Resveratrol protects chondrocytes from apoptosis via altering the ultrastructural and biomechanical properties: an AFM study. PLoS One 2014;9:e91611.

28 Wendling D, Abbas W, Godfrin-Valnet M, Guillot X, Khan KA, Cedoz JP, Baud L, Prati C, Herbein G: Resveratrol, a sirtuin 1 activator, increases IL- 6 production by peripheral blood mononuclear cells of patients with knee osteoarthritis. Clin Epigenetics 2013;5:10.

29 Latruffe N, Lancon A, Frazzi R, Aires V, Delmas D, Michaille JJ, Djouadi F, Bastin J, Cherkaou Exploring new ways of regulation by resveratrol involving miRNAs, with emphasis on inflamm Y Acad Sci 2015;1348:97-106.

-30 Park H, Huang X, Lu C, Cairo MS, Zhou X: MicroRNA-146a and microRNA-146b regula dendritic cell apoptosis and cytokine production by targeting TRAF6 and IRAK1 proter. 2015;290:2831-2841.

-31 Li JW, He SY, Feng ZZ, Zhao L, Jia WK, Liu P, Zhu Y, Jian Z, Xiao YB: MicroRNA-14 hypoxia-induced cardiomyocyte apoptosis. Mol Med Rep 2015;12:- 6910.

32 Nebreda AR, Porras A: p38 MAP kinases: beyond the stress respe 260.

-33 Papachristou DJ, Papadakou E, Basdra EK, Baltopoulos P, Panagiotop of the p38 MAPK-NF-kappaB signal transduction pa degeneration in humans. Mol Med 2008;14:160-166

-34 Tergaonkar V: NFkappaB pathway: a good signaling pa Biol 2006;38:1647-1653.

-35 Barnes PJ, Karin M: Nuclear factor-kappaB: a pivot N Engl J Med 1997;336:1066-1071.

36 Pomerantz JL, Baltimore D: Two pathway

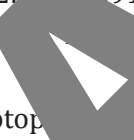
Papu assiliou AG: Involvement pathobiology of meniscus nd therapeutic target. Int J Biochem Cell
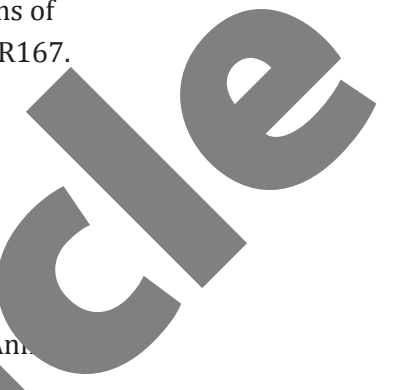